Supporting Information

\title{
Aqueous RAFT Polymerization of Acrylonitrile
}

\author{
Maciej Kopeć, Pawel Krys, Rui Yuan and Krzysztof Matyjaszewski*
}

Center for Macromolecular Engineering, Department of Chemistry, Carnegie Mellon University, 4400 Fifth Avenue, Pittsburgh, PA 15213, USA

* Corresponding author

Email:km3b@andrew.cmu.edu 


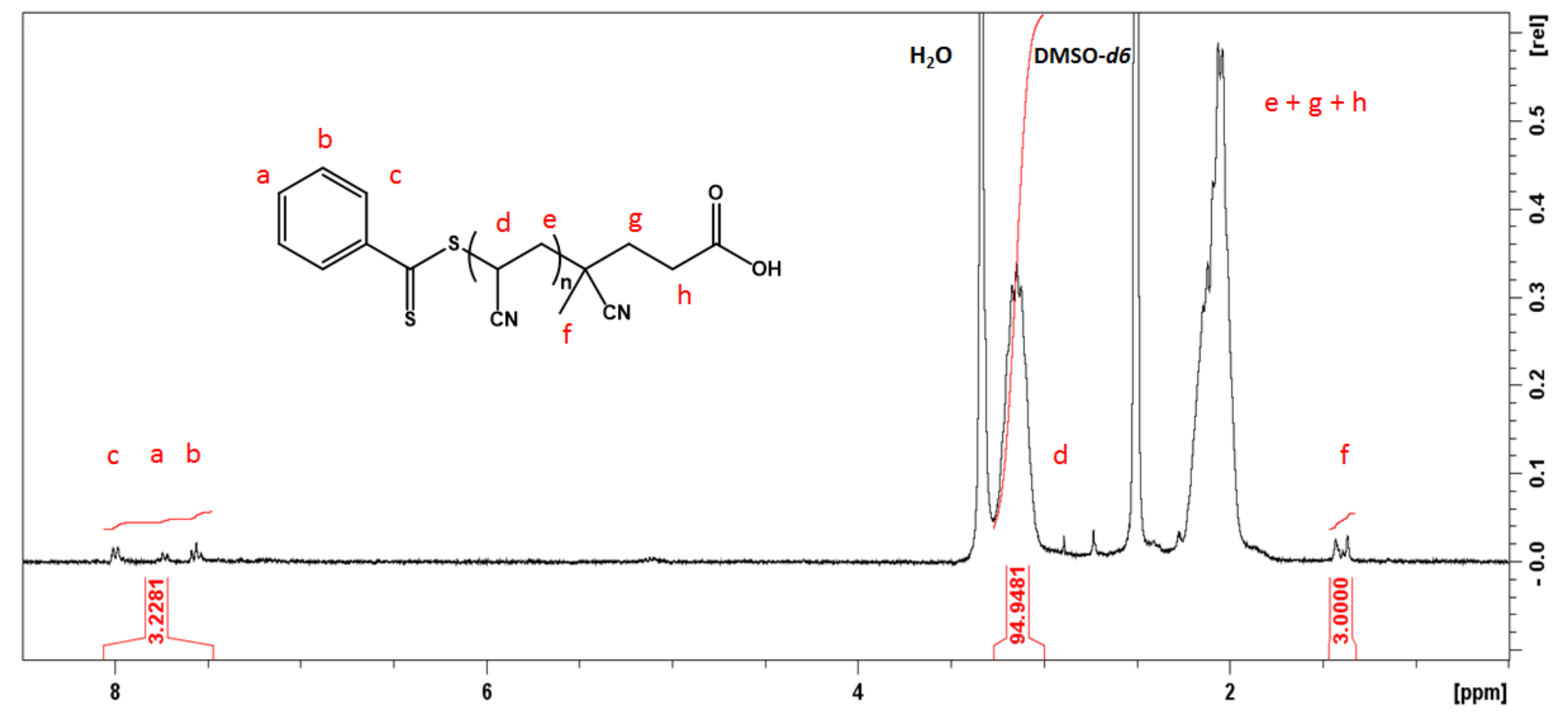

Figure S1. ${ }^{1} \mathrm{H}$ NMR spectrum of PAN sample $\left(M_{\mathrm{n}, \mathrm{GPC}}=6,900, M_{\mathrm{n}, \mathrm{NMR}}=5,300, M_{\mathrm{w}} / M_{\mathrm{n}}=1.24\right)$ synthesized by RAFT in aqueous solution of NaSCN and used for the chain extension experiment. $[\mathrm{AN}]_{0}:[\mathrm{CPAD}]_{0}:[\mathrm{AIBN}]_{0}=250: 1: 0.4, \mathrm{AN}: 50 \mathrm{wt} . \%$ aq. $\mathrm{NaSCN}=1: 1.5(\mathrm{v} / \mathrm{v}) ; T=65$ ${ }^{\circ} \mathrm{C}, 8$ hours. 


\section{Deconvolution of GPC Peaks}

Samples for GPC were prepared by drying small samples of the reaction mixture under a stream of air in order to remove water and then re-dissolving in DMF. Since NaSCN remained in the samples it could be seen on the eluogram. In almost all samples the salt peak was clearly separated from the polymer peak. However, for samples with low targeted DP $\left(\mathrm{DP}_{\text {target }}=100\right)$ and samples with low monomer conversion (and thus low molecular weight) the signals partially overlapped with the salt peak. Therefore, deconvolution was necessary. Peak fitting was conducted using Gaussian fit. $M_{\mathrm{w}} / M_{\mathrm{n}}$ are likely lowered due to symmetry of the fitted peaks, which does not account for any possible tailing. An example of such a fitting is provided in Figure S2. Astra software required careful adjustment of parameters to properly display full GPC traces and correctly calculate molecular weights.

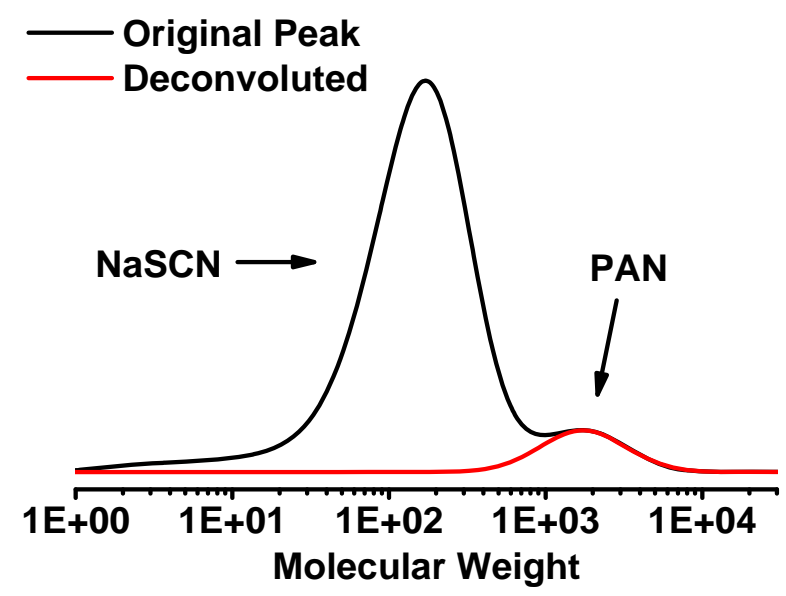

Figure S2. Example of peak deconvolution. $[\mathrm{AN}]_{0}:[\mathrm{CPAD}]_{0}:[\mathrm{AIBN}]_{0}=100: 1: 0.4$. Sample taken 6 hours into reaction $\left(39 \%\right.$ monomer conversion, $\left.M_{\mathrm{n}, \mathrm{th}}=2355, M_{\mathrm{n}, \mathrm{GPC}}=1855\right)$. 


\section{UV-Vis Studies}
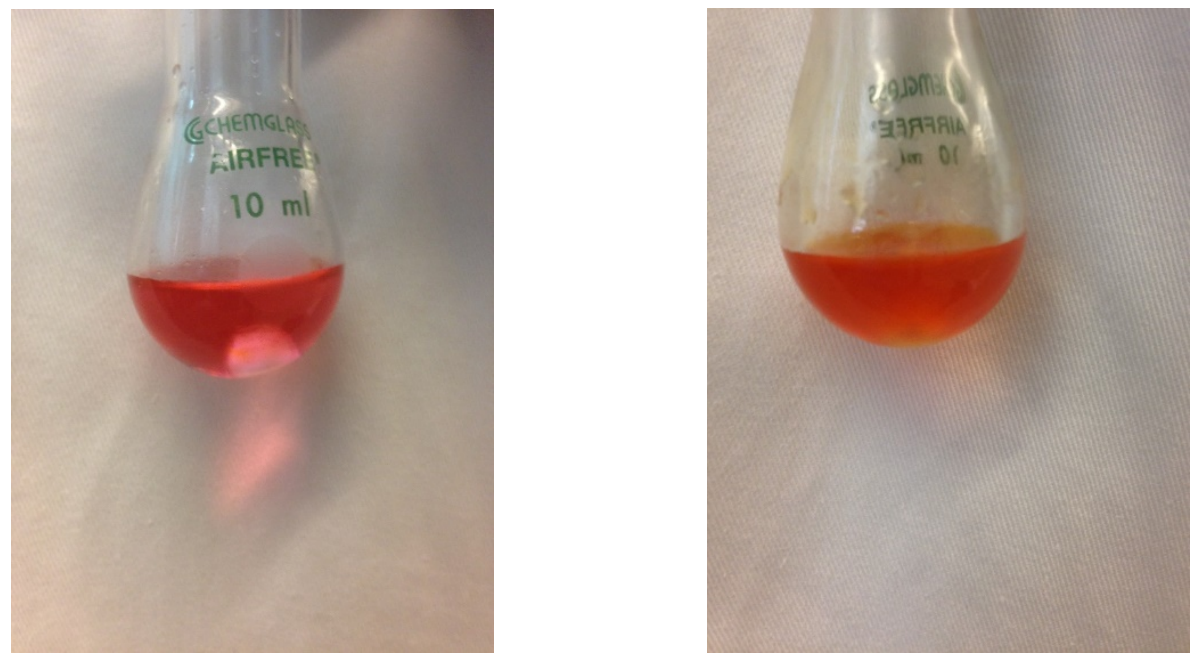

Figure S3. Digital images of the reaction mixture before (left) and after 24 hours reaction at 65 ${ }^{\circ} \mathrm{C}$ (right). [AN]:[CPAD]:[AIBN] = 500:1:0.4; AN:50 wt.\% aq. $\mathrm{NaSCN}=1: 1.5(\mathrm{v} / \mathrm{v})$.

A color change of the reaction mixture after $24 \mathrm{~h}$ of polymerization is shown in Figure S3. While this is usually attributed to degradation of dithiobenzoate moieties due to hydrolysis or aminolysis under basic conditions, and thus loss of chain-end functionality, ${ }^{1-3}$ other potential pathways of CPAD degradation were reported. Castignolles et al. observed a similar color change during polymerization of dimethyl(methacryloyloxy)methyl phosphonate using CPAD in acetonitrile. It was accompanied by a loss of control as attributed to trace oxygen residue in the reaction which would oxidize the CTA. ${ }^{4}$ Gilbert et al. investigated side reactions in CPADmediated RAFT of MAA and MMA in dioxane or toluene. The side product was identified to be dithiobenzoic acid (DTBA) that was formed to a larger extent when low MWs were targeted. ${ }^{5}$ On the other hand, DTBA was shown to react with PMMA macroradicals in situ to form new RAFT agents able to control the polymerization. ${ }^{6}$ Additionally, as thiocyanates are moderate nucleophiles, substitution of dithiobenzoate moieties with $\mathrm{SCN}^{-}$anions via the $\mathrm{S}_{\mathrm{N}} 2$ mechanism should be considered as a possible degradation pathway, given the large excess of $\mathrm{NaSCN}$ in the system. ${ }^{7,8}$ 

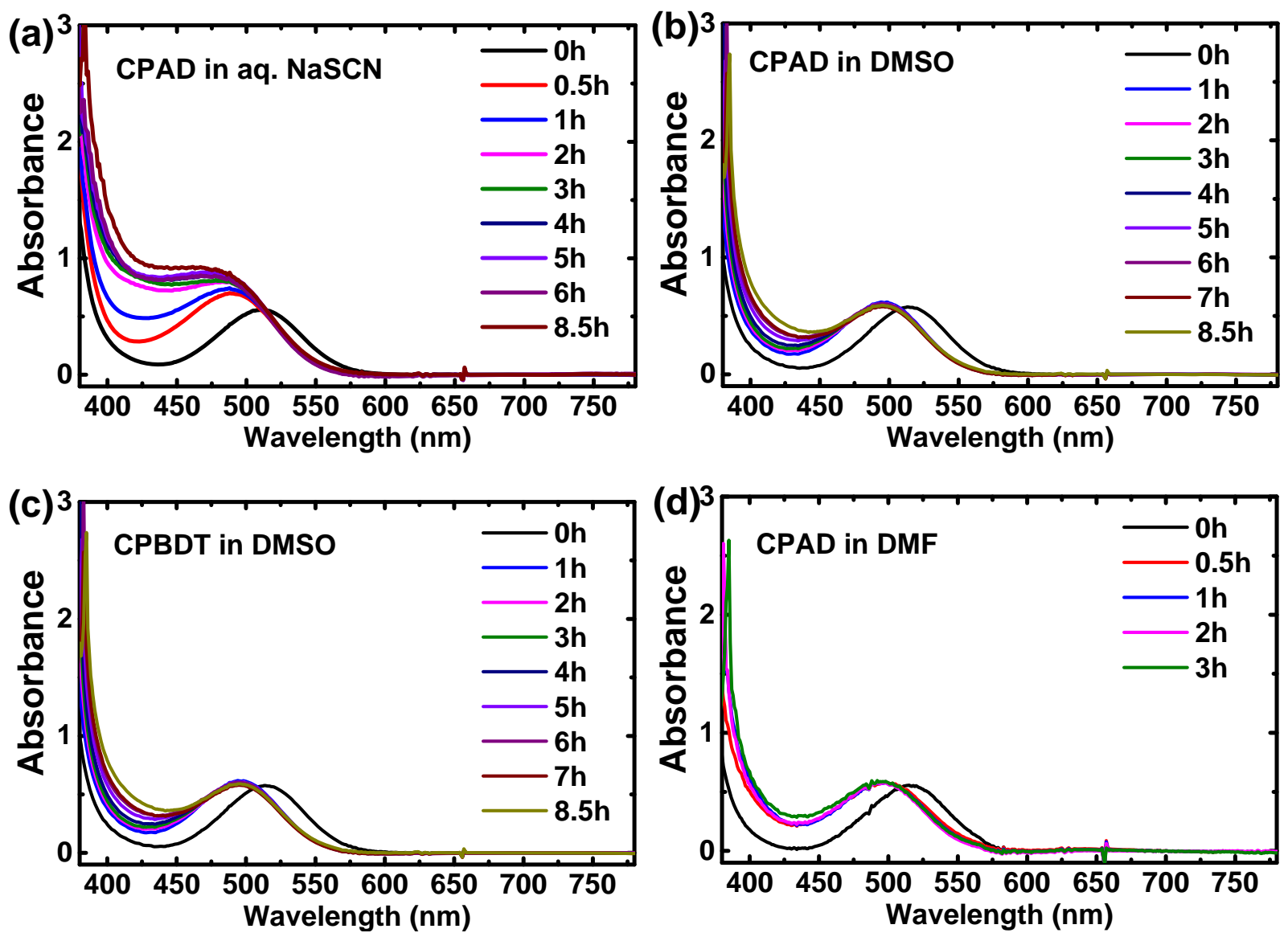

Figure S4. Evolution of absorbance in time during RAFT polymerization of AN in (a) aqueous NaSCN with CPAD; [AN]:[CPAD]:[AIBN] = 1000:1:0.4, AN:50 wt.\% aq. NaSCN = 1:1.5 (v/v); $\mathrm{T}=65^{\circ} \mathrm{C}$; (b) DMSO with CPAD; [AN]:[CPAD]:[AIBN] = 1000:1:0.4, AN:DMSO = 1:1.5 $(\mathrm{v} / \mathrm{v}) ; \mathrm{T}=65^{\circ} \mathrm{C}$; (c) DMSO with CPBDT; [AN]:[CPBDT]:[AIBN] = 1000:1:0.4, AN:DMSO = $1: 1.5(\mathrm{v} / \mathrm{v}) ; \mathrm{T}=65^{\circ} \mathrm{C}$; (d) DMF with CPAD; [AN]:[CPAD]:[AIBN] = 1000:1:0.4, AN:DMF = $1: 1.5(\mathrm{v} / \mathrm{v}) ; \mathrm{T}=65^{\circ} \mathrm{C}$;

Indeed, UV-Vis studies revealed a shift of the dithiobenzoate band from $510 \mathrm{~nm}$ to $490 \mathrm{~nm}$ after $0.5 \mathrm{~h}$ of reaction at $65^{\circ} \mathrm{C}$ and a development of a new broad band between 400 and $450 \mathrm{~nm}$ (Figure S4a). Thus, polymerization of AN in DMSO was conducted using CPAD as well as CPBDT to evaluate the influence of solvent on stability of dithiobenzoate-based RAFT agents. In both cases, a similar shift of the dithiobenzoate band was observed in the UV-Vis spectrum (Figure 3b and 3c). Reaction carried out with CPAD in DMF also changed color, although PAN precipitated out after 3 hours (Figure S4d). Furthermore, a control experiment revealed that color change was slower without AIBN added to the degassed mixture of CPAD, AN and aqueous NaSCN, but still occurred at both $65^{\circ} \mathrm{C}$ and room temperature (Figure S5). This could 
be due to slower substitution at the tertiary carbon atom of CPAD, than at a secondary dithiobenzoate-terminated carbon of a growing PAN chain. However, analogous experiment performed in DMSO also revealed a progressive shift in the dithiobenzoate band, in the presence or absence of AN, respectively (Figure S6). This points out that possible side reaction and/or degradation of dithiobenzoate chain end was not specific to the thiocyanate species. Degradation of dithiobenzoate-terminated polymethacrylates in DMSO was reported previously, but the reason behind this behavior remains unclear. ${ }^{9}$ Indeed, as demonstrated by the chain extension experiments (Figure 3 in the main text), retardation was more pronounced in DMSO than in aqueous $\mathrm{NaSCN}$ which would suggest less degradation in the aqueous system. When CPAD was dissolved in $\mathrm{AN}$ alone, in the absence of any additional solvent and radical initiator, no shift in the absorption spectrum was observed after $48 \mathrm{~h}$ at $65^{\circ} \mathrm{C}$.
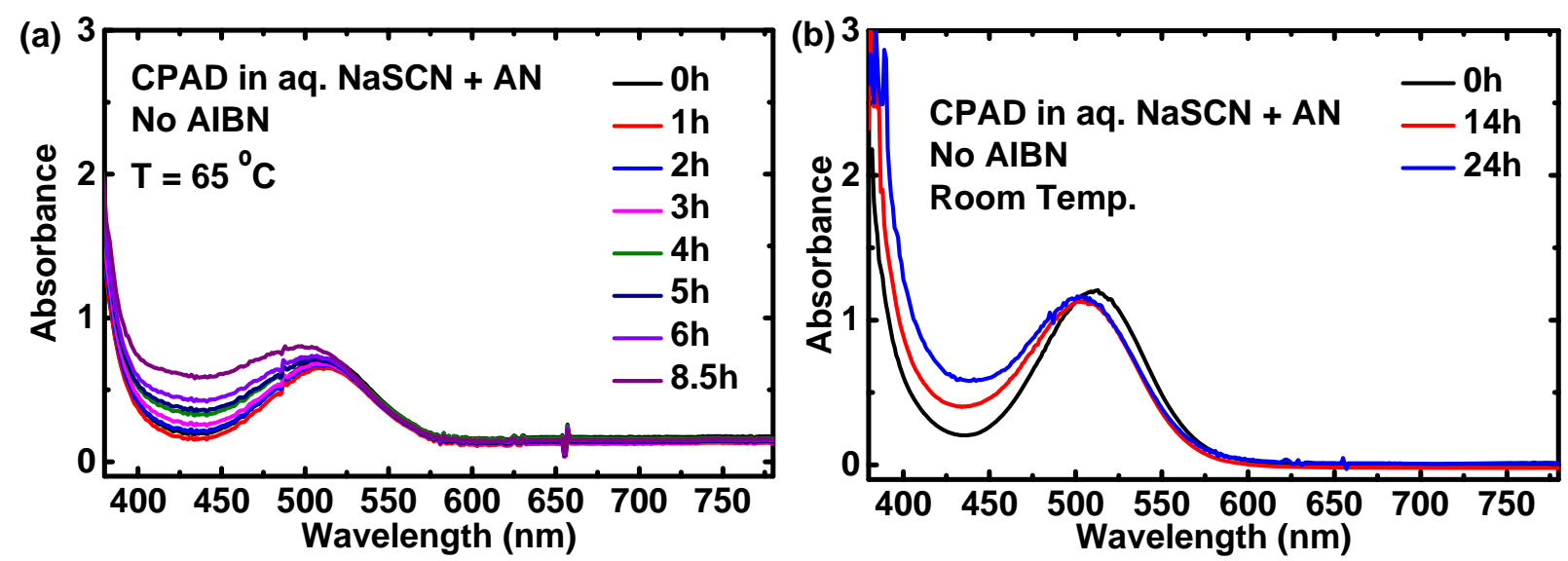

Figure S5. UV-Vis spectra of CPAD dissolved in a mixture of AN and aqueous $\mathrm{NaSCN}(50 \%$ wt.) in the absence of radical initiator at (a) $65^{\circ} \mathrm{C}$ and (b) room temperature. $[\mathrm{AN}]_{0}:[\mathrm{CPAD}]_{0}=$ (a) $1000: 1$ or (b) $250: 1$. AN:50 wt. \% aq. $\mathrm{NaSCN}=1: 1.5(\mathrm{v} / \mathrm{v})$. 

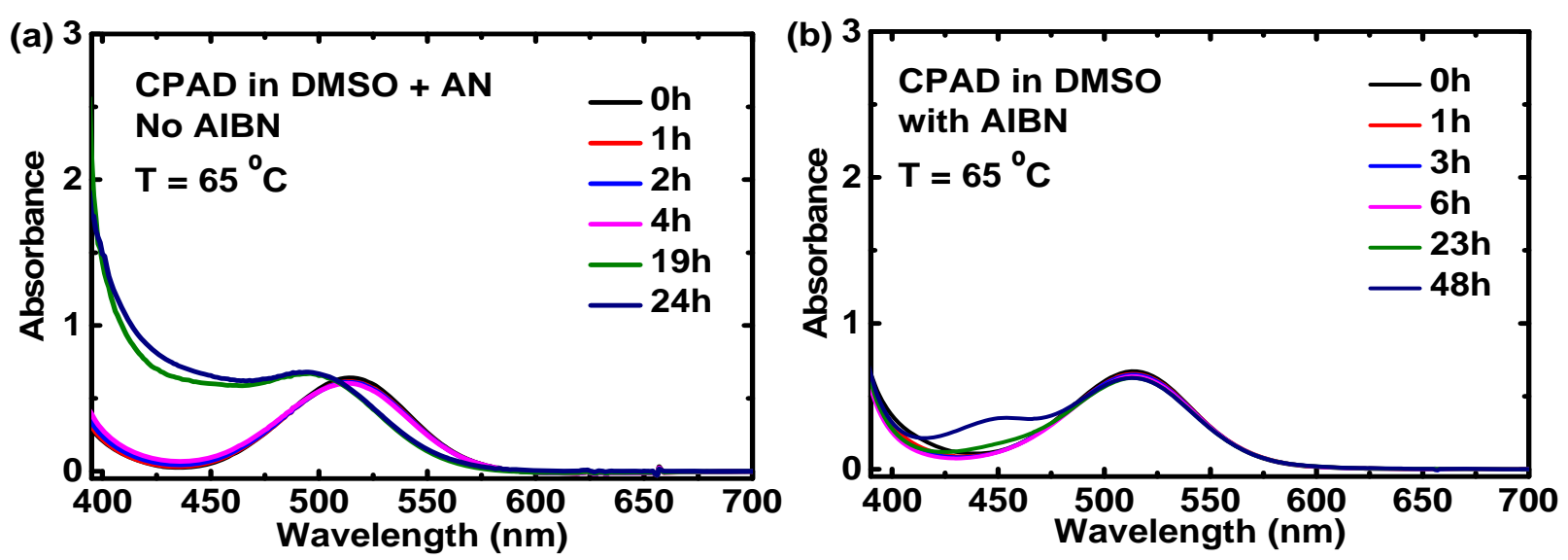

Figure S6. UV-Vis spectra of CPAD dissolved in (a) mixture of AN and DMSO in the absence of radical initiator $\left(\mathrm{c}_{\mathrm{CPAD}}=2 \mathrm{mg} / \mathrm{ml}\right.$, AN:DMSO $\left.=1: 1(\mathrm{v} / \mathrm{v})\right)$ and (b) DMSO with addition of $\operatorname{AIBN}\left(\mathrm{c}_{\mathrm{CPAD}}=2 \mathrm{mg} / \mathrm{ml}, \mathrm{c}_{\mathrm{AIBN}}=1 \mathrm{mg} / \mathrm{ml}\right)$ at $65^{\circ} \mathrm{C}$.

Chain-end functionality determined by NMR from phenyl peaks (Figure S1) was between 0.5 and 0.7 for all synthesized polymers which could indicate degradation of dithiobenzoate end groups. However, the excellent chain extension efficiency indicate that structural changes did not affect the overall RAFT mechanism and a shift in the absorption of the end group could be due to a formation of dithiobenzoate-terminated PAN macroradical. A further study to clarify this process is currently underway. 


\section{Determination of PAN Tacticity}

${ }^{13} \mathrm{C}$ NMR was conducted in DMSO- $\mathrm{d}_{6}$ on a $500 \mathrm{MHz}$ spectrometer. Fraction of triads was obtained by integrating $\mathrm{C} \equiv \mathrm{N}$ carbons $(\sim 120 \mathrm{ppm})$ or $\mathrm{C}-\mathrm{H}$ carbons $(\sim 28 \mathrm{ppm})$. The triad signals of $\mathrm{C} \equiv \mathrm{N}$ carbons were partially overlapping and therefore deconvolution was necessary. $\mathrm{C}$ - $\mathrm{H}$ carbon peaks were clearly separated in all samples.

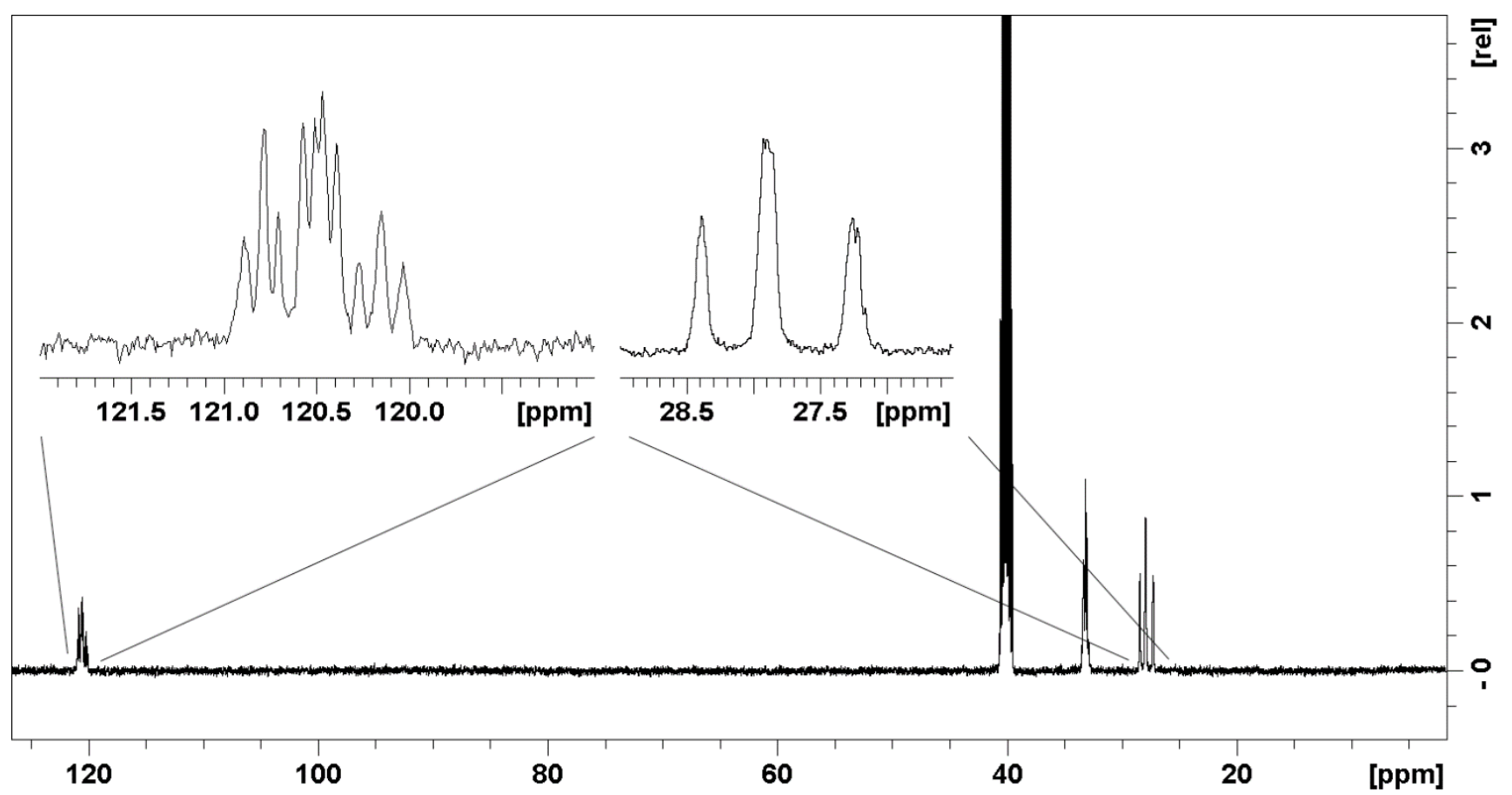

Figure S7. ${ }^{13} \mathrm{C}$ NMR spectra of PAN. $[\mathrm{AN}]_{0}:[\mathrm{CPAD}]_{0}:[\mathrm{AIBN}]_{0}=250: 1: 0.4, \mathrm{AN}: 50 \mathrm{wt} . \%$ aq. $\mathrm{NaSCN}=1: 1.5(\mathrm{v} / \mathrm{v}) ; T=65^{\circ} \mathrm{C}$. Final DP $=93\left(M_{\mathrm{n}, \mathrm{NMR}}=5,300\right)$. 


\section{References}

1. Thomas, D. B.; Convertine, A. J.; Hester, R. D.; Lowe, A. B.; McCormick, C. L., Macromolecules 2004, 37, 1735-1741.

2. $\quad$ Gregory, A.; Stenzel, M. H., Prog. Polym. Sci. 2012, 37, 38-105.

3. Albertin, L.; Stenzel, M. H.; Barner-Kowollik, C.; Davis, T. P., Polymer 2006, 47, 10111019.

4. David, G.; Asri, Z. E.; Rich, S.; Castignolles, P.; Guillaneuf, Y.; Lacroix-Desmazes, P.; Boutevin, B., Macromol. Chem. Phys. 2009, 210, 631-639.

5. Hosseini Nejad, E.; Castignolles, P.; Gilbert, R. G.; Guillaneuf, Y., J. Polym. Sci., Part A: Polym. Chem. 2008, 46, 2277-2289.

6. $\quad$ Nguyen, D. H.; Vana, P., Aust. J. Chem. 2006, 59, 549-559.

7. Levesque, G.; Arsène, P.; Fanneau-Bellenger, V.; Pham, T.-N., Biomacromolecules 2000, 1, 400-406.

8. $\quad$ Ju, Y.; Kumar, D.; Varma, R. S., J. Org. Chem. 2006, 71, 6697-6700.

9. Moad, G., Macromol. Chem. Phys. 2014, 215, 9-26. 